\title{
DIE KLOOF TUSSEN ROME EN DIE PROTESTANTISME
}

Die Kerkhervorming het ten doel gehad om die Kerk te herstel en van die vele misbruike wat daar in die loop van die voorafgaande eeue ingesluip het, te suiwer. Die Hervorming veronderstel dan ook dat daar 'n vervorming, ' $n$ misvorming was. Hierdie misvorming het plaasgevind omdat die Kerk nie meer uit die Skrif geleef het nie maar uit die wysbegeerte. Die Skolastiek, die kerklike wysbegeerte van die Middeleeue, het in die Kerk heerskappy gevoer. Menslike insettings en menslike redeneringe het die Bybel uit die lewe van die Kerk teruggedring en dit was hierteen dat die Hervormers hulle verset het. Die Protestantisme in die algemeen en die Hervormde Kerk in die besonder, het van twee beginsels uitgegaan wat in die vorige eeu die formele en die materiële beginsel genoem is. Die Hervormers self en die Protestantse Belydenisskrifte het nie hierdie onderskeiding gemaak nie, maar dit lê tog in die Protestantse teologie opgeslote. In die formele of objektiewe beginsel gaan dit om die vraag hoe die mens aan die kennis van die ewige waarheid kom en waar daardie waarheid te vinde is. Die antwoord wat die Hervormers daarop gegee het, was dat die Heilige Skrif die enige kenbron vir daardie ewige waarheid is, van die weg ter saligheid. Die mens moet hom dan ook vir die gesag van die Skrif buig. In die materiële of die subjektiewe beginsel kom die vraag weer aan die orde wat die waarheid is waardeur die mens geregverdig word. Die antwoord hierop is dat die mens deur die geloof geregverdig word en dat die saligheid van die mens van God afhanklik geag moet word. God openbaar Hom in die Skriftuur sowel as in die natuur maar die weg tot saligheid is alleen in die Skriftuur te vinde. Naas die Skrif word niks anders gestel nie. Geen onfeilbare kerkleer nie, geen onfeilbare menslike oorlewering nie, geen onfeilbare menslike woord nie. Alleen die Woord van God is onfeilbaar. Hier is dan ook die groot verskil, die groot teenstelling tussen die Middeleeuse Skolastiek en die Hervormde teologie: die Middeleeuse Skolastiek het die menslike woord naas en gelyk met die Woord van God gestel, terwyl die Hervormers alleen uit die Skrif wou put. Die studie van die Skrif het hulle die eerste gestel, en daarom was hulle sulke grote eksegete. Die Hervormde dogmatikus moet dan ook in die eerste plek skrif-verklaarder wees. Sy kennis van die dogmatiek moet hy in die eerste plek uit die Skrif haal. Dit is die formele beginsel. In die tweede plek haal hy dit uit die belydenis van die Kerk. Die Hervormde dogmatikus bou op die Skrif en nie op Luther, of Calvyn, of dr. Abr. Kuyper of Karl Barth nie. Dit was die suiwer Reformatoriese standpunt wat deur die keur- 
vors Frederik die Vrome, die geestelike vader van die Heidelbergse Kategismus, in 1563 uitgespreek is : „Ons erken God lof dat ons Christene is, in die naam van Christus gedoop, en nie in die naam van $Z$ wingli, van Calvyn of van Luther nie. Ons hou hierdie manne en anderes vir mense en werktuie van God; deur wie $\mathrm{Hy}$, soos dit vir ons toeskyn, baie goeds in die wêreld tot stand gebring het; ons neem aan dat hulle baie goeds geskryf het maar ook baie gedwaal het; sodat ons dan ook die geskrifte van hierdie en ander mense in soverre aanneem as wat dit met Gods Woord ooreenstem en al die orige laat ons vaar, net soos hulle self ook wil dat daarmee gehandel sal moet word."

Die eerste Reformatore het nie in die minste daaraan gedink om die Kerk, waarin hulle opgegroei het, los te laat nie. Die Kerk moes aan die hand van die Skrif gesuiwer word. Maar Rome het dit vir hulle onmoontlik gemaak. Rome het die dwaalleer waarteen die Hervormers beswaar gemaak het, nie alleen geduld en bevestig nie, maar as ewige onveranderlike waarhede geproklameer en wel op so 'n wyse dat Rome self hierdie dwaalleer nie weer kan loslaat sonder om sy eie bestaan op te hef nie. Dit is gedoen deur die Konsilie van Trente, 1545-1563, wat die Woord Gods en die woord van die mens van gelyke betekenis verklaar het; deur die pouslike proklamering van die dogma van die Onbevlekte Ontvangenis van Maria in 1854 waardeur die Maria-verering bykans die verering van Christus oorskadu; en deur die Vatikaanse Konsilie van 1870 toe die Onfeilbaarheid van die Pous tot kerklike leerstuk verklaar is, waardeur die Roomse Kerk gevaar loop om nie meer Christelike maar Pouslike Kerk te wees.

Vóór die Konsilie van Trente was dit nog moontlik vir die Protestante en die Rooms Katolieke om kerklik mekaar te ontmoet, maar na Trente is dit uitgesluit. Teenoor die beginsel dat die Heilige Skrif algenoegsaam is om die weg ter saligheid uit te leer ken, het Trente geleer dat die kerklike oorlewering van gelyke gesag is as die Skrif en dat die Skrif alleen deur die Kerk uitgelê kan en mag word, en dat hierby die Latynse Vulgaat die offisiële teks van die Skrif is. Onder die oorlewering word verstaan die som van alles wat in sake wat tot die geloof en sedes behoort, deur Christus self of deur sy Apostels self alleen mondeling voorgedra is en deur die genade van die Heilige Gees onafgebroke en onvervals deur die Kerk bewaar is, al is dit ook nie op skrif gestel nie. $\left.{ }^{1}\right)$

En wat die Skrif betref, het Trente vasgestel dat die Apokriewe boeke ook kanonieke gesag het, net soos die ander Bybelboeke. En van hierdie Skrif is die Latynse Vulgaat, 'n ou Latynse vertaling wat op baie plekke foutief vertaald is, die gesaghebbende teks. En alleen die Roomse Kerk is bevoeg om die Heilige Skrif uit te lê.

1) Konsilie van Trente, vierde sitting. 
Met ander woorde, waar die Hervormers hulle vir hul leerstellings en teenoor die dwaalleer van Rome op die Heilige Skrif beroep, daar het die Konsilie van Trente drie dinge naas die Skrif gestel, gelyk met die Skrif, as grond vir sy dwaalleer, naamlik die kerklike oorlewering waarin juis hierdie dwaalleer opgeneem is, die Apokriewe boeke waarin sommige van die Roomse ketterse stellings mee bewys word, en die Latynse vertaling waarvan die foutiewe vertaling ook die ketterse stellings moet steun. As voorbeeld van die laaste noem ons hier twee Bybel tekste, Genesis 3 vers $15 \mathrm{~b}$ en Genesis 48 vers 16 . Genesis 3 vers $15 \mathrm{~b}$ word ooreenkomstig die Hebreeuse teks as volg vertaal: Hy sal jou die kop vermorsel, en jy sal hom in die hakskeen byt. Christus, die tweede Adam, sal die kop van die slang vermorsel. Die Vulgaat lees egter: $S y$ sal jou die kop vermorsel. Hierdie Sy is dan Maria, die twreede Eva! Hierdie foutiewe lesing van die Vulgaat dien dan as bewys-plek vir die Maria-kultus. In Genesis 48 waar Jacob die seuns van Josef seën, vertaal ons vers 16 ooreenkomstig die Hebreeuse teks: mag deur hulle my naam genoem word en die naam van my vaders Abraham en Isak. Die foutiewe lesing van die Vulgaat is: Laat my naam aangeroep word oor hulle en ook die name van my vaders Abraham en Isak. Hierdie foutiewe lesing van die Vulgaat moet dan dien as bewysplek vir die aanroeping van die heiliges.

Verder is die Kerk, dit wil sê die Pous, die enigste uitlegger van die Skrif. Die wat dit nie aanvaar nie, moet in die ban gedoen word, ge-ekskomuniseer, want vir hom is daar geen plek in die Kerk nie; hy is ' $n$ uitgeworpene wie se mening nie meetel nie. Rome het dit dus afgesny en onmoontlik gemaak om met die Protestante in gedagtewisseling oor die leerstellige geskilpunte te hou.

In 1564, 'n jaar na die sluiting van die Konsilie, het pous Pius IV die Professio Fidei Tridentinae uitgevaardig wat 'n samevatting is van die leerstellings wat deur die Konsilie vasgestel is. Dit is bindend gemaak vir alle waardigheidsbekleders en leeraars in die Roomse Kerk en word ook gebruik as belydenis wat die Protestant moet aflê wat na Rome oorgaan. Dit bestaan uit twaalf artikels waarvan die eerste die Belydenis van Nicea bevat. Ons gee dit hier in Afrikaanse weer omdat mens daarin die Roomse kerkleer kortliks saamgevat vind, behalwe die dogma van die Onbevlekte Ontvangenis van Maria wat eers in 1854, en die van die Pouslike Onfeilbaarheid wat eers in 1870 vasgestel is:

I. Ek N.N. glo en bely met 'n vaste geloof alles en ieder van die stukke van die geloofssimbool wat die heilige Roomse Kerk gebruik, nl. :

\section{(en dan volg die Niceense Belydenis)}

II. Ek neem mees standvastiglik aan en ek omhels die apostoliese en kerklike oorlewerings en alle andere gebruike en bepalings van die selfde Kerk. 
III. Ek neem ook die Heilige Skrif aan, ooreenkomstig daardie sin waarin onse heilige Moederkerk dit gehou het en hou, aan wie dit toekom om oor die ware betekenis en uitlegging van die Skrifte te oordeel; en ek sal dit nooit anders neem en uitlê nie dan volgens die unanieme ooreenstemming van die Vaders.

IV. Ek bely ook dat daar waarlik en by uitstek sewe sakramente van die nuwe wet is, deur Jesus Christus onse Heer ingestel, en nodig vir die saligheid van die mense, hoewel nie vir almal en elkeen nie, naamlik die doop, die vormsel, die avondmaal, die boete, die laaste oliesel, die priesterwyding en die huwelik; en dat dit genade gee; en dat hiervan die doop, die vormsel en die priesterwyding nie sonder heiligskennis herhaal kan word nie. Ook erken en aanvaar ek die aangenome en goedgekeurde seremonies van die Katolieke Kerk wat by die plegtige toediening van die voornoemde sakramente gebruik word.

$V$. Ek omhels en neem aan alles in die geheel en afsonderlik van wat in die heilige Konsilie van Trente oor die erfsonde en regverdiging bepaal en verklaar is.

VI. Netso bely ek dat in die mis ' $n$ ware, werklike en versoenende offer vir die lewendes en die dodes aan God geoffer word; en dat die liggaam en bloed saam met die siel en die godheid van onse Here Jesus Christus waarlik reëel en wesenlik (substantialiter) in die allerheiligste sakrament van die avondmaal is; en dat daar ' $n$ verandering is van die hele wese van die brood in die liggaam, en van die hele wese van die wyn in die bloed; watter verandering die Katolieke Kerk transubstansiasie noem.

VII. Ek bely ook dat Christus onder ieder afsonderlike gedaante (specie) in sy geheel in 'n ware sakrament genuttig word.

VIII. Ek hou standvastiglik dat daar ' $n$ vagevuur is en dat die siele wat daar gehou word, gehelp word deur die gebede van die gelowiges. Netso, dat die heiliges wat met Christus regeer, vereer en aangeroep moet word en dat hulle gebede aan God vir ons offer en dat hul relieke vereer moet word.

IX. Ek verklaar as beslis waar dat die beelde van Christus en van die Moeder Gods die onbevlekte Maagd asook van die ander heiliges daar moet wees en behou moet word en dat die verskuldigde eer en verering daaraan gegee moet word. $E_{k}$ bevestig dat die krag van die aflate deur Christus in die Kerk gelaat is en dat die gebruik daarvan baie heilsaam vir die Christenmense is.

$\mathrm{X}$. Ek erken die heilige Katolieke Apostoliese Kerk van Rome as die moeder en meesteres van alle Kerke; en ek beloof en sweer troue gehoorsaamheid aan die Biskop van Rome, opvolger van 
die heilige Petrus, die Prins van die Apostels en die Plaasvervanger van Jesus Christus.

XI. Netso neem ek aan en bely ek sonder twyfel alle ander dinge wat deur die Heilige Kanons en Algemene Sinodes en in die besonder deur die heilige Konsilie van Trente oorgelewer, bepaal en verklaar is; en ek veroordeel, verwerp en verban alles wat, daarmee teenstrydig is en alle kettery wat die Kerk veroordeel verwerp en uitgeban het.

XII. Op hierdie oomblik bely en handhaaf ek waarlik, uit eie, vrye wil, hierdie ware Katolieke geloof waarsonder niemand salig kan word nie; en ek beloof baie standvastiglik om dieselfde met Gods hulp tot aan die einde van my lewe in sy geheel ongeskonde te behou en te bely. En ek sal sover as dit in my vermoë is sorg dra dat dit deur my ondergeskiktes of die waarvan die sorg onder my amp val, gehou, geleer en gespreek sal word. Dit beloof, beëdig en sweer ek - so helpe my God, en hierdie heilige Evangelies van God.

Deur die besluite van die Konsilie van Trente het Rome die Protestantse leer nie alleen veroordeel nie maar die Protestante self ook as uitgebannes uit die Kerk verklaar, as ketters met wie daar geen geestelike gemeenskap gehou kan word nie. Waar die Protestante hulle alleen op die Heilige Skrif beroep, daar bou Rome op 'n ander Heilige Skrif, naamlik op 'n Latynse vertaling wat op baie plekke foutief is en wat ook die Apokriewe boeke bevat wat deur die Protestante nie as Heilige Skrif erken word nie. Verder word die oorlewering naas en gelyk met die Skrif gestel wat bowedien ook nog alleen deur die Roomse Kerk uitgelê mag word. Rome en die Protestante kon mekaar voortaan nie meer op dieselfde bodem ontmoet nie.

Maar daar het nog meer gebeur. In 1854 het pous Pius IX 'n nuwe dogma afgekondig, die dogma van die Onbevlekte Ontvangenis van die Maagd Maria. Die Maria-verering dateer al vanaf die vierde eeu na Christus en is heeltemal heidens van oorsprong. In die Nuwe Testament word dit nie geleer nie. Hierdie Maria-verering het later oorgegaan in in Maria-vergoding. In die gebede van die Roomse Kerk word sy genoem die Koningin van die engele, die Koningin van die Aartsvaders. En tot haar word gebid: „die hele wêreld vereer u as die dogter van die ewige Vader. U sit met $u$ Seun aan die regterhand van die Vader." Hierdie Maria-vergoding het uitgeloop op die afkondiging van die dogma van die Onbevlekte Ontvangenis. Maria was dan nie alleen sonder dadelike sonde nie, maar was ook sonder erfsonde. Sy was nie soos die ander mense in sonde ontvang en gebore nie. 
Die Dekreet waarin Pius IX in 1854 hierdie dogma afgekondig het, lui as volg:

.Nademaal ons nooit opgehou het om in nederigheid en in vaste onse gebede en die gebede van die Kerk op te stuur aan God die Vader deur sy Seun, sodat Hy dit mag waardig keur om onse gemoed deur die krag van die Heilige Gees te bestuur en te bevestig, na die afsmeking van die beskerming van die hele hemelse hof, en na aanroeping op onse knieë van die Heilige Gees die Parakleet, kondig ons af, verklaar en bepaal ons tot die glorie van die Heilige ondeelbare Triniteit, die eer en versiering van die heilige Maagd die Moeder van God, tot die verheffing van die Katolieke geloof en die vermeerdering van die Christelike godsdiens, deur die gesag van onse Here Jesus Christus en die geseënde Apostels Petrus en Paulus, en op ons eie gesag, dat die leet wat inhou dat die Geseënde Maagd Maria vanaf die eerste moment van haar ontvangenis deur 'n besondere genade en voorreg van die Almagtige God, met die oog op die verdienstes van Christus Jesus die Saligmaker van die mensheid van die bevlekking van die erfsonde bewaar is, deur God geopenbaar is, en daarom standvastiglik en voortdurend deur alle gelowiges geglo moet word. Daarom as sommige mense hul mag verstout om in hul harte anders te dink as wat ons bepaal het (hetgeen God verhoede) moet hulle weet en terdege verstaan dat hulle deur hul eie oordeel veroordeel is, dat hul geloof skipbreuk gely het, en hulle van die eenheid van die Kerk weggeval het; en verder dat hulle deur hierdie daad hulle onderhewig gemaak het aan die strawwe wat deur die wet vasgestel is as hulle in woord of geskrif of op enige ander uiterlike wyse durf te kenne gee wat hulle in hul harte dink."

Met hierdie leerstuk wat elke lid van die Roomse Kerk verplig is om te aanvaar, het die kloof tussen Rome en die Protestantisme dieper en breër geword. Van Christelike Kerk het die Roomse Kerk Mariakerk geword. Maria word deur hierdie leerstuk uit die gevalle en verloste geslag van Adam uitgelig en gelyk met die Verlosser geplaas, want as sy geen erfsonde of daadsonde het nie, dan het sy ook geen verlossing nodig nie. Berou, vergiffenis, wedergeboorte, bekering, heiligmaking is op haar dan net so min van toepassing as op Christus self. Die Mariadiens oorskadu Christus in die Roomse erediens. In die afbeeldings wat van haar gegee word is sy gewoonlik die moeder wat die kindjie Jesus in die arms het. Dit is nie Christus wat die kop van die slang vermorsel het nie maar, soos pous Pius IX dit uitgedruk het, Maria het dit ",met haar onbevlekte voet" gedoen. Sy word in die plek van die Heilige Gees gestel en word tot middelares tussen Christus en die gelowige gemaak. En die „Ave Maria" is vir die Roomse wat die Onse Vader vir die Protestant is. 
In 'n Rooms-Katholieke dogmatiek word van haar gesê dat Sy "with her Son was to overcome Satan"2). Dus, die.verlossingswerk is nie die werk van Christus alleen nie, maar van Christus tesame met Maria. Hier volg 'n paar verdere aanhalings uit die genoemde dogmatiek: „The co-operation of the Mother with the Redeemer who was her Son differs not only in degree, but also in kind, from that of any other saint. For her consent alone he waited when he sent Gabriel to her presence. She alone is his Mother; she alone, as the second Eve, stood beneath the Cross"3). Dus, die engel Gabriel is nie deur God na Maria gestuur om haar mee te deel dat sy geboorte sou gee aan 'n kind, die kind Jesus nie, maar hy is deur Jesus na Maria gestuur om haar toestemming te vra dat $\mathrm{Hy}$ uit haar gebore kon word. So lees ons dan ook verder op dieselfde bladsy van hierdie dogmatiek: "In the New Testament we are shown the picture of Mary saluted by the Angel, Mary in obedience unparalleled on earth, Mary in her deep humility, Mary giving utterance of her Fiat - be it done unto me according to thy word' - Mary overshadowed by the Spirit of God, Mary the chosen vessel of election, Mary the Mother of the Word, and then after her years of union with her Son in the holy house of Nazareth Mary beneath the Cross, the head of Satan crushed, man delivered. The Fathers of the Church supply the commentary when they teach us how the Mother of God undid the work of Eve". En daarom kan die skrywer verderaan sê "Mary is the cause of our salvation" word verder genoem ,the eldest daughter of the Father, and the beloved Mother of the Son, and the chosen Spouse of the Everlasting Spirit"s). Sy is die Felix caeli porta, die geluksalige hemelpoort. Dit behoef geen betoog dat soiets volkome in stryd is met die onderrig wat Christus self aan sy dissipels gegee het nie. Waar Hy self sê: ,Ek is die deur; as iemand deur My ingaan, sal hy gered word", daar sê Rome dat Maria die deur is waardeur mens moet ingaan om gered te word.

Die Maria-cultus het in die Roomse Kerk vanaf die dae van die Middeleeue in ergerlikheid toegeneem, en as illustrasie hiervan word enkele voorbeelde aangehaal uit die Katolieke Gesang- en Gebedeboek wat in 1941 met die Imprimatur van die Roomse Kerk in Afrikaans verskyn het $\left.{ }^{\circ}\right)$. Nadat haar tussenkoms afgesmeek is om van God vergiffenis van sonde te kry, word in een gebed gesê: „U voorspraak, liefste Moeder bly voorwaar nooit onverhoord" (bls. 1). In 'n ander gebed word God gevra dat ons deur die Moeder van Christus, die Laagd Maria, ,die vreugdes van die ewige lewe verkry”, (bls. 4). En

2) The Teaching of the Catholic Church, a Summary of Catholic Doctrine arranged and edited by Canon George Smith. D.D., Ph.D., two volumes, London, 1948, Vol. I p. 55.

3) Vol. I p. 529-530.

4) bls. 531 .

5) bls. 548 .

6) Gedruk te Oudtshoorn, Kaapprovinsie, deur die Pallotti Pers. 
„daar ek nou aan U behoort, o goeie Moeder, behoed en beskerm my as u eiendom en besitting", (bls. 7); dus waar die Skrif leer dat die verlostes die eiendom van Christus is, 1 Korinthiërs 3 vers 23 en Titus 2 vers 14, daar leer Rome dat die verlostes die eiendom en besitting van Maria is. Sy word in een van die gebede genoem "Middelares tussen God en die mense, liefde van die sterflikes en hul hemelse lig", (bls. 160) en dit terwyl die Skrif sê „daar is een God en een Middelaar tussen God en die mense, die mens Jesus Christus", 1 Tim. 2 vers 5. Vir die Protestant is Jesus Christus die Middelaar tussen God en die mense maar vir die Roomse is Maria die Middelares tussen Jesus Christus en die mense en word vir die sterwende gebid: "Mog die barmhartigste Maagd Maria, vriendelikste Vertroosteres van hulle wat treur, die siel van haar dienaar aan haar Seun beveel, opdat deur haar moederlike voorspraak hy die dood nie mag vrees nie, maar in vreugde die hemelse woning mag ingaan", (bls. 191). Aan Maria word dan ook in die gebede die wonderlikste name gegee, soos Magtige Maagd, Setel van die wysheid. Geestelike Vat, Geheimnisvolle Roos, Toring van Dawid, Ivore Toring, Goue Huis, Ark van die Verbond, Deur van die Hemel, Toevlug van die Sondaars, Hulp van die Christene, Koningin van die Engele, Koningin van die Aartsvaders, Koningin van die Profete, Koningin van die Apostels, Koningin van die Martelaars, Koningin van die Belyers, Koningin van die Heiliges, Koningin van die Heilige Rosekrans (bls. 66, 67). Die hele wêreld vereer haar ,as die dogter van die ewige Vader" en ",al die hemelse geeste roep onophoudelik: Gans heilig is U, o Maria, Moeder van God en Maagd" (bls. 160). En verder word in die gebed tot haar gesê: „Die glorieryke leër van die belyders noem $U$ die tempel van die heiligste Drievuldigheid. Die hele hemelse hof eer $U$ as Koningin. $U$ is die Koningin van die engele, die poort van die paradys. Leer tot die glorie van die hemel, troon van God, ark van versoening en genade. Kanaal van genade, Bruid en Moeder van die ewige Koning. $U$ is die tempel en heiligdom van die Heilige Gees, tabernakel van die allerheiligste Drievuldigheid. $U$ is die Gebiedster van die wêreld en Koningin van die hemel, na God ons enigste hoop. U lei die regverdiges, bring terug die dwalendes, in Jesus is $U$ aan die profete voorspel. Deur $U$ is vervul die woord van die profete, $U$ is die leermeesteres van die apostels en evangeliste. U sit met u seun aan die regterhand van die Vader" (bls. 160 en 161). In 'n ander gebed weer lui dit: „O Moeder, sien neer op ons, u kinders, en verwaardig $U$ om ons huldiging aan te neem. Ons glo en bely as getrou Katolieke: $U$ is die altyd onbevlekte, altyd reine, altyd maagdelike, die altyd triomferende oorwinnares wat vir die slang die kop vermorsel het. Hoe helder is $U$, die stralende Môre-ster van ons verlossing! So wonderlik mooi en ryk aan eer en mag, so heerlik 
en verhewe bo alle engele en heiliges, die naaste by die troon van $u$ goddelike Seun" (bls. 162).

Dat dit alles met die Heilige Skrif in stryd is, behoef geen betoog. Dit moet dan ook nie uit die oog verloor word nie dat die Maria-leer, net soos die leer aangaande die heiliges soos deur die Roomse Kerk bely word, nie Bybels nie maar heidens van oorsprong is. Dit is met die Heilige Skrif in teenspraak en die Protestant wat nie alleen in naam nie maar daadwerklik op die bodem van die Skrif staan, kan dit uit die aard van die saak nie aanvaar nie. Die stuk heidendom wat in die Roomse kerkleer opgeneem is en wat ieder gelowige lid van die Roomse Kerk moet aanvaar en bely, is onverenigbaar met die geloof in Jesus Christus soos dit in die Heilige Skrif geleer word.

Rome kan hierdie stuk heidendom egter nie meer loslaat nie en ' $n$ hervorming in die Roomse Kerk op leerstellig gebied, soos die Reformatore vóór die dae van die Konsilie van Trente op gehoop het, is vergoed uitgesluit want, as Rome hierdie onbybelse leerstelling wat op Trente en later vasgestel is, sou loslaat, dan sou die Roomse Kerk hom self ophef en vernietig. Die leerstellings van die Konsilies is deur die Pous goedgekeur en daarom is dit volgens Rome as leerstellings deur die Heilige Gees geïnspireer en onfeilbaar. In 1870 het die Vatikaanse Konsilie as dogma vasgestel dat, ,wanneer die Pous ex cathedra praat, dit wil sê, wanneer hy optree in die amp van herder en leraar van al die Christene, kragtens sy opperste apostoliese gesag en hy 'n leer in verband met die geloof en die sedes bepaal wat deur die ganse Kerk gehou moet word, hy deur die goddelike bystand wat aan hom in die geseënde Petrus beloof is, in die besit is van daardie onfeilbaarheid waarmee die goddelike Verlosser wou dat sy Kerk mee begiftig moet wees in die bepaling van ' $n$ leer in verband met die geloof en sedes; en dat sulke bepalings van die Roomse Opperpriester uit hulle self onveranderlik (irreformabiles) is en nie deur die konsent van die Kerk verander kan word nie. Maar as enigiemand, wat God verhoede, waag om hierdie bepaling te weerspreek, dan moet hy uitgeban word (anathema sit)."

Hierdie dogma van die onfeilbaarheid van die Pous vind geen steun nog in die Heilige Skrif, nog in die oorlewering. Daar kan histories bewys word dat daar Pouse was wat in hulle hoedanigheid van herders en leraars van die ganse Christenheid, soos hulle voorgegee het, gedwaal het en ketters was, maar Rome wil nog kán dit toegee. Allerhande uitvlugte word gesoek, soos in die geval van pous Honorius I (625-638) wat in twee briewe aan Sergius, Patriarg van konstantinopel, ex cathedra die Monotheletiese kettery geleer het wat deur die tweede Konsilie van Konstantinopel in 553 veroordeel was. En Honorius is in 680 op die derde Konsilie van Konstantinopel as ketter veroordeel en 'n ewige anathema is oor hom uitgespreek. Die apologete van die onfeilbaarheidsleer kom hier egter met allerhande uitvlugte om die 
saak reg te praat: die een beweer dat die dokumente nie eg is nie, die ander dat dit geen kettery was wat Honorius geleer het nie, en $n$ derde dat Honorius nie ex cathedra sou gepraat het nie. Daar is baie bewyse uit die Skrif sowel as uit die geskiedenis van die Kerk wat teen hierdie leer van die sogenaamde onfeilbaarheid van die Pous aangevoer kan word, maar ons volstaan met te verwys na die boek van professor George Salmon: The Infallibility of the Churchi ${ }^{\top}$ ).

Dr. S. D. van Veen, in lewe professor in die Kerkgeskiedenis aan die Universiteit van Utrecht, sê in verband met hierdie leerstuk die volgende: .De Roomsche kerk heeft nu ook feitelijk opgehouden een christelijke kerk te $z \mathrm{ijn}$; $z \mathrm{ij}$ is geworden, thans eerst ten volle, de kerk, niet meer van Christus, maar van den paus, niet van den herder maar van den beheerscher der zielen. $Z_{i j}$ is bovendien, door haar besluiten over de machtsvolkomenheid van den paus, een macht geworden, meer nog dan vroeger gevaarlijk voor den staat, gevaarlijk voor de vrijheid, gevaarlijk voor elk, die het waagt haar te weerstaan"8). Waar die $\mathrm{Re}-$ formatore in die begin nog iets van in gesprek met Rome verwag het, daar het so 'n gesprek onmoontlik geword. Die kloof tussen Rome en die Protestantisme het na die Kerkhervorming al hoe breër en dieper geword en ten slotte heeltemal onoorbrugbaar, eers deur die Konsilie van Trente in die sestiende eeu, daarna deur die afkondiging van die leer van die Onbevlekte Ontvangenis van Maria in 1854, en ten slotte deur die vasstelling van die dogma van die Onfeilbaarheid van die Pous op die Vatikaanse Konsilie in 1870. En in ons dae is die Pous besig met die bepaling van 'n nuwe dogma, die leerstuk van die sogenaamde hemelvaart van Maria, waardeur die onoorbrugbare kloof tussen Rome en die Protestantisme nog groter sal word.

S. P. ENGELBRECHT. 